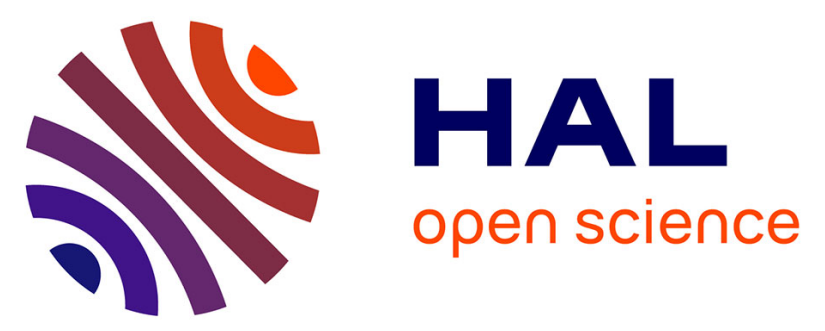

\title{
Sizing Optimization Methodology of a Surface Permanent Magnet Machine-Converter System over a Torque-Speed Operating Profile: Application to a Wave Energy Converter
}

\author{
Judicael Aubry, Hamid Ben Ahmed, Bernard Multon
}

\section{To cite this version:}

Judicael Aubry, Hamid Ben Ahmed, Bernard Multon. Sizing Optimization Methodology of a Surface Permanent Magnet Machine-Converter System over a Torque-Speed Operating Profile: Application to a Wave Energy Converter. IEEE Transactions on Industrial Electronics, 2011, pp.1-1. 10.1109/TIE.2011.2163287 . hal-00612935

\section{HAL Id: hal-00612935 \\ https://hal.science/hal-00612935}

Submitted on 1 Aug 2011

HAL is a multi-disciplinary open access archive for the deposit and dissemination of scientific research documents, whether they are published or not. The documents may come from teaching and research institutions in France or abroad, or from public or private research centers.
L'archive ouverte pluridisciplinaire HAL, est destinée au dépôt et à la diffusion de documents scientifiques de niveau recherche, publiés ou non, émanant des établissements d'enseignement et de recherche français ou étrangers, des laboratoires publics ou privés. 


\title{
Sizing Optimization Methodology of a Surface Permanent Magnet Machine-Converter System over a Torque-Speed Operating Profile : Application to a Wave Energy Converter
}

\author{
Judicaël Aubry, Hamid Ben Ahmed and Bernard Multon, Member, IEEE
}

\begin{abstract}
This paper sets forth a sizing optimization methodology of a surface permanent magnet machine-converter system over a torque-speed operating profile. The two optimization objectives are to minimize the cost of the machine-converter system and to minimize (or maximize) electrical energy consumption (or generation). The optimization parameters serve to describe both the machine geometry and the electrical ratings of the electronic power converter. Each operating point of the profile is treated independently, and current control is optimized at every operating point in order to not only minimize machine drive losses but also satisfy several constraints and then implicitly considering fluxweakening possibility. This optimization methodology is generic and is applied to a particular case: a direct-drive conversion chain for a wave energy converter. We show that taking into account both the sizing parameters of the converter and the fluxweakening control, in addition to the classical sizing parameters of the machine, has a strong impact on the machine-converter system optimal results. Moreover, the strong coupling with the wave energy converter through damping parameters, plays also a crucial role on the sizing results.
\end{abstract}

Index Terms-Design optimization, energy efficiency, fluxweakening control, pareto optimization, permanent magnet machines, power electronic converters, variable speed drives, wave energy conversion.

\section{NOMENCLATURE}

$(\alpha, \gamma) \quad$ Converter cost coefficients

$\beta \quad$ Viscous damping coefficient of the WEC

$\Delta \Theta \quad$ Winding temperature rise

$\Phi_{e} \quad$ Flux linkage of the PM per phase (r.m.s value)

$\Phi_{f} \quad \sqrt{3} \Phi_{e}$

$\Omega_{i} \quad$ Angular velocity of the $i^{t h}$ operating point

$B_{i} \quad$ Local flux density for the $i^{\text {th }}$ operating point

$B_{\text {sat }} \quad$ Constraint level of flux density

$B_{s w, r e c}$ Switching and recovery losses coefficient

$c_{x} \quad$ Specific cost of the material $x$

$C_{\text {conv }}$ Cost of the power electronic converter

$C_{\text {drive }}$ Cost of the machine-converter system

Manuscript received December 16, 2010. Accepted for publication May 16, 2011. Paper no. 10-2225-TIE.

Copyright (c) 2011 IEEE. Personal use of this material is permitted. However, permission to use this material for any other purposes must be obtained from the IEEE by sending a request to pubs-permissions@ieee.org.

J. Aubry, H. Ben Ahmed, and B. Multon are with the Laboratoire Systèmes et Application des Technologies de l'Information et de l'Énergie (SATIE), École normale supérieure de Cachan Bretagne, Centre National de la Recherche Scientifique (CNRS), Université Européenne de Bretagne (UEB), F-35170 Bruz, France (e-mail : judicael.aubry@bretagne.ens-cachan.fr)
$C_{\text {mach }}$ Cost of the machine
$d_{i} \quad$ Cumulated duration of the $i^{t h}$ operating point
$E_{\text {elec }} \quad$ Electrical energy converted
$f_{s w} \quad$ Switching frequency of the converter
$H_{i} \quad$ Local field intensity for the $i^{\text {th }}$ operating point
$H_{s} \quad$ Significant wave height of the sea state
$I_{\text {rated }}$ Rated current of the power electronic converter
$L_{l} \quad$ Leakage inductance per phase
$L_{m} \quad$ Magnetizing inductance per phase
$M_{x} \quad$ Total mass of the material $x$ (iron ,magnet, copper)
$P_{\text {average }}$ Average produced electrical power
$P_{\text {cond }}$ Power electronics conduction losses
$P_{\text {copper }}$ Copper losses
$P_{\text {iron }}$ Iron losses
$P_{l e v} \quad$ Levelling power of the WEC
$P_{\text {loss }} \quad$ Machine-converter system losses
$P_{s w} \quad$ Power electronics switching losses
$R_{d, x} \quad$ Dynamic resistance of $x$ (diode or igbt) component
$R_{f} \quad$ Equivalent iron loss resistance
$R_{s} \quad$ Armature resistance per phase
$R_{t h} \quad$ Thermal resistance
$S_{\text {conv }}$ Apparent power of the power electronic converter
$T_{i} \quad$ Electromagnetic torque of the $i^{\text {th }}$ operating point
$T_{p} \quad$ Spectral peak period of the sea state
$U_{D C} \quad$ DC bus voltage
$V_{0, x} \quad$ Threshold voltage of $x$ (diode or igbt) component
$V_{\text {rated }}$ Rated voltage of the power electronic converter

The geometric parameters of the electromagnetic structure of the machine are defined in Table II.

\section{INTRODUCTION}

T HIS article proposes to develop and apply a sizing optimization methodology of a surface permanent magnet machine(SPM)-converter system over a torque speed operating profile. The term "operating profile" refers herein to a series of torque-speed operating points denoted $\left(T_{i}, \Omega_{i}\right)$. From the moment that variable speed is required and even more if field weakening too, the sizing process of a machine-converter system must not only include the machine dimensions but also the power electronic converter ratings. Furthermore, performances (e.g. losses) of the machine-converter system must be calculated over the whole operating profile. These two facts compel us to adopt an original sizing process. 
The first original feature is to deal with the more realistic operating profile. Indeed in the literature, a broad majority of sizing methods are only based on one typical torque-speed operating point [1]-[5], which can be difficult to define for variable-speed applications [6]. Some others approaches are based on a base point and a flux weakening point [7]. This is not necessarily easier to define.

The second original feature is to consider the machine and the power electronic converter as a whole. Indeed, the sizings and ratings of each component are strongly interdependent [8]. For example, the flux-weakening capability of the machine will have a high impact on the ratings of the converter, especially if the operating profile presents a constant power speed range [9]. That is why the proposed methodology will include a current control strategy (direct and transverse axis current) in order to contribute to the extension of the constant speed power range [10], [11] but also the minimization of losses [12]-[14]. This consideration will take the form of an $\left(i_{d}, i_{q}\right)$ optimization to minimize losses at each operating point of the profile respecting some constraints (voltage, current, demagnetization...) [15]. Research to date have been limited to optimizing the control strategy and machine geometry (excluding the converter) [16], or optimizing the control-convertermachine system while focusing on just a single criterion (e.g. the machine mass [17] or total cost of the system [18], [19]).

In the proposed methodology, the sizing parameters of the machine and the current rating of the power electronic converter ( $\propto$ silicon area) are optimized together according two objective functions. The first optimization objective is the minimization of the machine-converter system cost, which is here considered as the sum of the cost of raw materials mass for the active parts of the machine and the cost of the power electronic converter. The calculation of the average system losses over the operating profile enables to determine the second optimization objective which is the electrical energy. All the operating points of the profile are taken into account to determine objectives and satisfy constraints.

The first part of the paper will present the sizing methodology of the machine-converter system on an operating profile. In the second part, we will apply this approach and consider a direct drive generator and its power electronic converter of a wave energy converter (WEC) as an example. A strong coupling is shown between the optimization of damping parameters of the WEC and the sizing parameters of the machine-converter system. This paper constitutes a follow-up of the conference article [20]. This methodology proves to be generic and applicable to any system in which a machineconverter system is operating at variable speed, like for electric traction or renewable energy conversion.

\section{PRESENTATION OF THE OPTIMIZATION PROBLEM}

An optimization problem consists in defining one or more objectives, depending on one or more parameters, subjects to one or more constraints.

\section{A. Optimization Objectives}

1) First Objective : Cost of the machine-converter system: In order to evaluate the cost of the machine-converter system
$C_{d r i v e}$, we consider the sum of the power electronics cost (converter, filters, control circuits) and machine cost:

$$
C_{\text {drive }}=C_{\text {conv }}+C_{\text {mach }}
$$

Our assumption is that the cost of the converter is a function of its apparent power $S_{c o n v}$ (2) (stemming from observations). Values of coefficients $\alpha$ and $\gamma$ remain valid for a given power range and conversion structure. These coefficients for an ACDC-AC IGBT (NPT) three-phase bridge are provided for the application example further below. As for the machine cost, only the sum of costs of different raw materials for active parts have been taken into account (3), with numerical values being listed in Table I. These costs are very sensitive to market prices and the values considered here are given in Table I for example purposes only.

$$
\begin{gathered}
C_{c o n v}=\alpha S_{c o n v}^{\gamma} \\
C_{m a c h}=c_{N d F e B} M_{N d F e B}+c_{F e} M_{F e}+c_{C u} M_{C u}
\end{gathered}
$$

where $c_{x}$ and $M_{x}$ are respectively the specific cost and the total mass of the material $\mathrm{x}$.

TABLE I

Cost PARAmeters

\begin{tabular}{llc}
\hline Symbol & Description & Value \\
\hline$\alpha$ & AC-DC-AC converter cost coefficients & 6.7 \\
$\gamma$ & Specific magnet cost & 0.7 \\
$c_{N d F e B}$ & Specific lamination cost & $30 € . \mathrm{kg}^{-1}$ \\
$c_{F e}$ & Specific copper cost & $3 € . \mathrm{kg}^{-1}$ \\
$c_{C u}$ & $6 € . \mathrm{kg}^{-1}$ \\
\hline
\end{tabular}

2) Second Objective : Electrical Energy: Depending on the specific application, whether motor or generator, the electrical energy may be either consumed or generated. The losses must be added to the mechanical power in motor case and subtract in generator case. Electrical energy $E_{\text {elec }}$ is expressed as follows:

$$
E_{\text {elec }}=\sum_{i}\left(T_{i} \Omega_{i} \pm P_{\text {loss }, i}\right) d_{i}
$$

where $P_{\text {loss }, i}$ are the total machine-converter system losses at operating point $\left(T_{i}, \Omega_{i}\right)$ with a cumulated duration $d_{i}$ over all the operating profile.

\section{B. Optimization Parameters}

The system to be optimized is an SPM machine-converter system. The optimization parameters thus need to describe the two physical components making up this system: machine and converter.

Let's assume the DC bus voltage $U_{D C}$ to be constant then the rated current $I_{\text {rated }}$ of the power electronic converter will then be parameterized by the apparent power $S_{\text {conv }}$ with $S_{\text {conv }}=3 V_{\text {rated }} I_{\text {rated }}$ and $V_{\text {rated }}=U_{D C} /(2 \sqrt{2})$ i.e. without accounting injection of third harmonic.

In order to effectively describe the machine, let's identify just the geometric parameters shown in Fig. 1 and listed in Table II. The design range of each parameter is also precised for the application further below. 


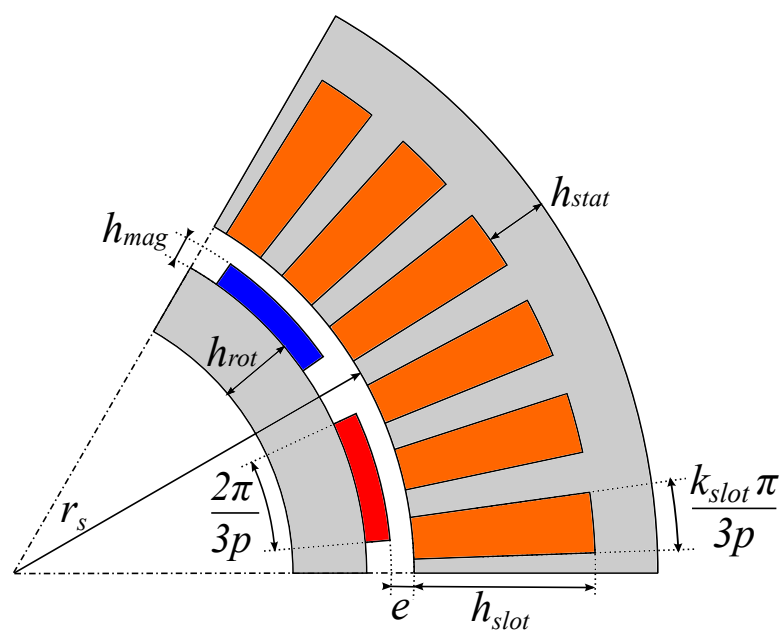

Fig. 1. Geometric parametrization of the SPM machine

TABLE II

OPTIMIZATION PARAMETERS

\begin{tabular}{llll}
\hline Symbol & Description & Range & Units \\
\hline$S_{\text {conv }}$ & $\begin{array}{l}\text { Apparent power of the power electronic } \\
\text { converter }\end{array}$ & {$[0.05 ; 10]$} & $M V A$ \\
$l_{u}$ & Active machine length & {$[0.1 ; 5]$} & $\mathrm{m}$ \\
$r_{s}$ & Inner stator radius & {$[2 ; 5]$} & $\mathrm{m}$ \\
$p$ & Number of poles pairs & {$[1 ; 500]$} & - \\
$e$ & Airgap length & {$[0.2 ; 100]$} & $\mathrm{mm}$ \\
$h_{\text {mag }}$ & Magnet height & {$[2 ; 200]$} & $\mathrm{mm}$ \\
$h_{\text {rot }}$ & Rotor yoke height & {$[0.1 ; 100]$} & $\mathrm{cm}$ \\
$h_{\text {slot }}$ & Slot height & {$[1 ; 200]$} & $\mathrm{cm}$ \\
$h_{\text {stat }}$ & Stator yoke height & {$[0.1 ; 500]$} & $\mathrm{cm}$ \\
$k_{\text {slot }}$ & Slot pitch to tooth pitch ratio & {$[0.3 ; 0.7]$} & - \\
$n_{s}$ & Number of turns in series per phase & $p \times[1 ; 10]$ & - \\
& (defined as the number of conductors & & \\
& per slot times the number of poles pairs) & & \\
\hline
\end{tabular}

\section{Optimization Constraints}

To complete the description of this optimization problem, several constraints still need to be defined.

Some constraints must be satisfied at each operating point $\left(T_{i}, \Omega_{i}\right)$. They can be qualified as instantaneous constraints:

- Rated voltage: $\forall i, \sqrt{v_{d, i}^{2}+v_{q, i}^{2}} \leq \sqrt{3} V_{\text {rated }}$

- Rated current: $\forall i, \sqrt{i_{d, i}^{2}+i_{q, i}^{2}} \leq \sqrt{3} I_{\text {rated }}$

where voltage and current in $\mathrm{d}$ - and q-axis are calculated from equivalents circuits on Fig. 2.

- Saturation $\forall i, \max \left(B_{i}\right) \leq B_{\text {sat }}$

which must be respected in each part of the machine (stator and rotor yoke and in teeth). This constraint only has to ensure the validity of the linear magnetic model.

- Demagnetization $\forall i, H_{i} \geq-H_{k}$

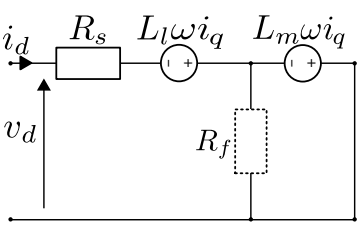

$d$-axis

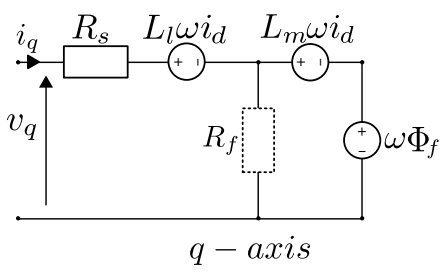

$q-a x i s$
Fig. 2. d- and q-axis equivalent circuits of the SPM machine
TABLE III

CONSTRAINT PARAMETERS

\begin{tabular}{llc}
\hline Symbol & Description & Value \\
\hline$U_{D C}$ & DC bus voltage & $1300 \mathrm{~V}$ \\
$r_{\max }$ & Maximum outer stator radius & $5 \mathrm{~m}$ \\
$B_{\text {sat }}$ & Maximum induction level & $1.5 \mathrm{~T}$ \\
$H_{k}$ & Permanent magnet coercivity & $760.10^{3} \mathrm{~A} \cdot \mathrm{m}^{-1}$ \\
$\Delta \Theta_{\max }$ & Maximum temperature rise & $110 \mathrm{~K}$ \\
\hline
\end{tabular}

Other geometrical constraints however must be satisfied for each machine, they can be qualified as global constraints:

- $e>0.2+3 \sqrt{r_{s} l_{s}}(\mathrm{~mm})$ [2]

- $r_{s}+h_{\text {slot }}+h_{\text {stat }} \leq r_{\text {max }}$

- $r_{s}-e-h_{m a g} \geq h_{\text {rot }}$

Lastly, the thermal constraint must be treated with special attention. The temperature rise of the hottest point relative to ambient temperature must be calculated strictly by means of a transient thermal model. The maximum value over the entire temperature rise profile must therefore remain below a threshold value : $\max (\Delta \Theta(t)) \leq \Delta \Theta_{\max }$

In order to avoid a temporal transient simulation which will increase excessively the optimization process computation time, only one steady-state thermal model may be used but only in two cases:

- When thermal time constants of the machine are large relative to the loss variation periods, the temperature rise constraint can be calculated based on average machine losses value. If we denote $\Delta \Theta_{i}$ the steady-state temperature rise for each operating point, the temperature rise constraint in this case can be rewritten : $\sum_{i} \Delta \Theta_{i} d_{i} / \sum_{i} d_{i}<\Delta \Theta_{\max }$

- When the thermal time constants are small relative to the loss variation periods, temperature rise may be considered as instantaneous and the corresponding constraint appears on the least favorable operating point: $\max \left(\Delta \Theta_{i}\right)<$ $\Delta \Theta_{\max }$

Depending on the application and level of power under consideration, one of these two cases may be envisaged. Otherwise, it would be necessary to calculate the temperature rise profile on the basis of a temporal resolution with a transient thermal model, which could cause higher computation time.

The constraint parameters used in the example further below are listed in the Table III.

\section{Local Current Vector Control Optimization}

In order to evaluate system losses $P_{\text {loss }, i}$ at each operating point $\left(T_{i}, \Omega_{i}\right)$, the direct axis current $i_{d, i}$ still needs to be determined. The transverse axis current $i_{q, i}$, in case of a nonsalient machine, is completely defined by the torque $T_{i}$ to be supplied.

As said previously, the field weakening can be very influent on the sizing of each component. It can improve the performance of the machine-converter system in two ways:

- The extension of the constant power speed range. In several articles [10], [11], it is shown that electronic flux weakening (through modification of the leading angle) makes it possible, for given converter ratings, to extend 


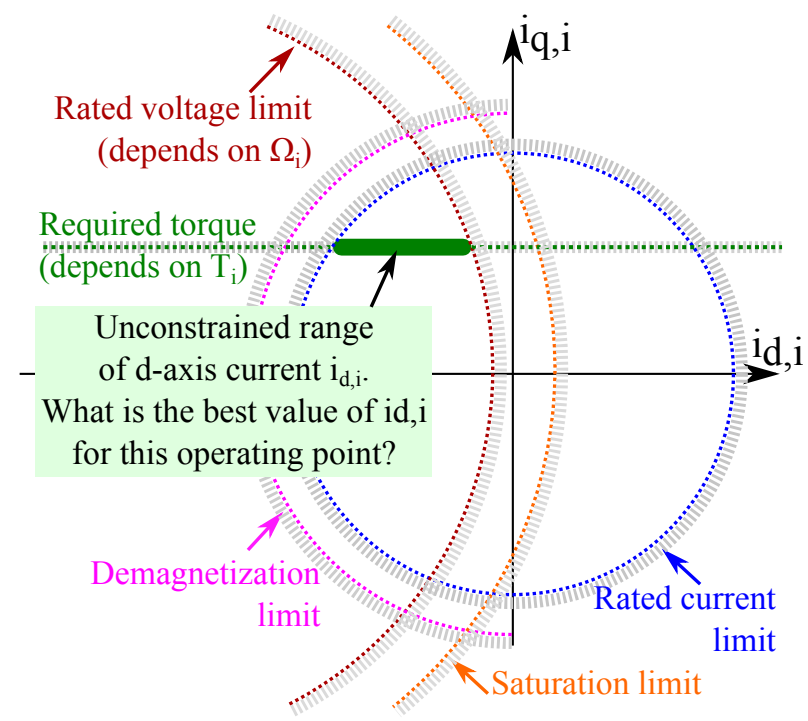

Fig. 3. Illustration of the d-axis current constrained optimization problem

the operating speed range of a machine-converter system with respect to a conventional control (i.e. an $i_{d}=0$ control).

- The minimization of losses [12]-[14]. By restricting losses to just copper losses, then loss minimization at each operating point necessitates a so-called "maximum torque per ampere" control, which within the scope of non-salient machines, may be expressed very simply as $i_{d}=0$. By adding other losses (magnetic, converter) to this formulation, the control law for minimizing losses at each point becomes more complex, while still remaining feasible.

Then the values of currents $i_{d, i}$ at each operating point should constitute strictly optimization parameters to the same extent as machine-converter system sizing parameters. Over an operating profile containing a large number of points however, this rigorous approach is infeasible since it leads to an excessive increase in the number of optimization parameters. The alternative approach adopted herein consists of locally optimizing the value of current $i_{d, i}$ for each operating point. Let's assign the minimization of total machine and converter losses $P_{\text {loss }}$ as the optimization criterion, which in turn contributes to optimizing one of the two global sizing objectives, namely electrical energy $E_{\text {elec }}$.

As indicated in the previous paragraph however, some instantaneous constraints must be satisfied at each operating point $\left(T_{i}, \Omega_{i}\right)$ : voltage, current, saturation and demagnetization. An illustration of these constraints is presented in Fig. 3. The value $i_{d, i}$ must therefore be optimized subject to these constraints. Should no optimization solution exist, i.e. no $i_{d, i}$ value found to satisfy all four instantaneous constraints, then the particular operating point cannot be reached. A new constraint will now be defined that encompasses the four mentioned above: each operating point $\left(T_{i}, \Omega_{i}\right)$ have to be reached (equivalent to a $i_{d, i}$ shall exist for each operating point $\left.\left(T_{i}, \Omega_{i}\right)\right)$.

In practice, this constrained optimization routine is per- formed by systematically computing several discrete values lying within the interval $\left[-I_{\text {rated }} ; 0\right]$ (a reduction of this interval is possible by calculating the corresponding d-axis current of intersection points between the iso-torque line and the constraints limits). The selected $i_{d, i}$ value is the one that minimizes losses while satisfying constraints. The number of computed discrete values will be established on the basis of a compromise between level of accuracy and computation time.

\section{MACHINE-CONVERTER System MOdelization}

\section{A. Electrical Machine Model}

The equivalent circuits in both axes are depicted in Fig. 2. Iron losses are taken into account in the sum of system losses. But they are not include in the calculation of electrical values. That is why the equivalent resistance $R_{f}$ is drawn in dotted line and does not appear in (5) and (6).

The decomposition into $\mathrm{d}-\mathrm{q}$ axis has been chosen so that the RMS current value per phase and the RMS phase to neutral voltage are both expressed as follows:

$$
\begin{gathered}
\sqrt{3} I=\sqrt{i_{d}^{2}+i_{q}^{2}} \\
\sqrt{3} V=\sqrt{\left(R_{s} i_{d}-\left(L_{m}+L_{l}\right) \omega i_{q}\right)^{2}+\left(R_{s} i_{q}+\omega\left(\left(L_{m}+L_{l}\right) i_{d}+\Phi_{f}\right)\right)^{2}}
\end{gathered}
$$

The electromagnetic torque equals:

$$
T=p \Phi_{f} i_{q}
$$

\section{B. Model of machine-converter system losses}

The resistance $R_{s}$ of one phase is determined from the set of geometric parameters. Copper resistivity is set at the maximum allowable temperature $\left(@ 130^{\circ} \mathrm{C}\right)$. The dependence of resistivity or other physical quantities on temperature could be incorporated by means of an iterative calculation, yet computation time would rise excessively. Total copper losses are then expressed as follows :

$$
P_{\text {copper }, i}=R_{s}\left(i_{d, i}^{2}+i_{q, i}^{2}\right)
$$

Iron losses are calculated in the first harmonic hypothesis. The consideration of harmonic losses in the model would not cause any additional difficulties. Equation (9) is used to calculate loss densities:

$$
p_{\text {iron }, i}=\frac{2 k_{H}}{\pi}\left|\Omega_{i}\right| \hat{B}_{i}{ }^{2}+\alpha_{p} \frac{\left(p \Omega_{i} \hat{B}_{i}\right)^{2}}{2}
$$

where $\hat{B}_{i}$ is the local flux density peak value for $i^{\text {th }}$ operating point. This value depends on the part of the machine. Loss coefficients $\alpha_{p}$ and $k_{H}$ are detailed in Table IV. Total iron losses are derived from (9) by summing total losses in both the teeth and stator yoke. Loss densities are considered to be homogeneous in each of these two parts (rotor losses are assumed to equal zero for this model in the first harmonic under steady-state mode).

Losses in the electronic power converter are composed of the sum of conduction losses (10) and switching losses (11) within both the diodes and transistors (in this case IGBT).

$$
P_{\text {cond }, x}=V_{0, x} I_{a v, x}+R_{d, x} I_{R M S, x}^{2}
$$


TABLE IV

CONSTANT PARAMETERS USED FOR THE APPLICATION FURTHER BELOW

\begin{tabular}{llc}
\hline Symbol & Description & Value \\
\hline$V_{0, I G B T}$ & Threshold voltage for each device & $2 \mathrm{~V}$ \\
$V_{0, \text { diode }}$ & & $1.7 \mathrm{~V}$ \\
$r_{d, I G B T}$ & Dynamic resistance for each & $1500 \mathrm{~m} \Omega \cdot A^{-1}$ \\
$r_{d, \text { diode }}$ & component per ampere-rating & $1000 \mathrm{~m} \Omega \cdot A^{-1}$ \\
$B_{s w, r e c}$ & Switching and recovery losses coefficient & $3 \mathrm{~mJ} \cdot \mathrm{A}^{-1}$ \\
$f_{s w}$ & Switching frequency & $2 \mathrm{kHz}$ \\
\hline$B_{r}$ & Remanent induction of permanent magnet & $1 \mathrm{~T}$ \\
$k_{f i l l}$ & Slot-filling coefficient & 0.4 \\
$k_{H}$ & Hysteresis loss coefficient & $90 \mathrm{~A} \cdot \mathrm{m} \cdot \mathrm{V}^{-1} \cdot \mathrm{s}^{-1}$ \\
$\alpha_{p}$ & Eddy current loss coefficient & $0.065 \mathrm{~A} \cdot \mathrm{m} \cdot \mathrm{V}^{-1}$ \\
$\rho_{C u}$ & Copper resistivity @ $130^{\circ} \mathrm{C}$ & $2.5 .10^{-8} \Omega \cdot \mathrm{m}^{-1}$ \\
$\lambda_{C u}$ & Equivalent thermal conductivity of winding & $0.5 \mathrm{~W} \cdot \mathrm{m}^{-1} \cdot \mathrm{K}^{-1}$ \\
$\lambda_{F e}$ & Radial thermal conductivity of laminations & $30 \mathrm{~W} \cdot \mathrm{m}^{-1} \cdot \mathrm{K}^{-1}$ \\
$h$ & Convective heat transfer coefficient & $10 \mathrm{~W} \cdot \mathrm{m}^{-2} \cdot \mathrm{K}^{-1}$ \\
\hline
\end{tabular}

where $x$ is the component under consideration (diode or IGBT), $V_{0, x}$ the threshold voltage of the device $x$ and $R_{d, x}$ its dynamic resistance. $I_{a v, x}$ and $I_{R M S, x}$ are respectively the average and RMS current passing through the device $x$. It depends on the RMS current per phase $I$ and voltage $V$ but also on the phase difference between these two quantities.

Switching losses are assumed to be proportional to the switched current:

$$
P_{s w}=f_{s w}\left(B_{s w, r e c}\right) I_{R M S} \sqrt{2} / \pi
$$

where $B_{s w, r e c}$ is the switching and recovery losses coefficient in the IGBT and diode. The hypothesis will be adopted whereby for a given maximum voltage rating (here $3300 \mathrm{~V}$ ), this coefficient remain independent of the maximum current rating of the switch.

Observations from manufacturers' documentation enable deducing, for a given maximum voltage rating (here $3300 \mathrm{~V}$ ), the scale law as a function of the maximum current rating of the two components:

$$
\begin{aligned}
& V_{0, x} \text { and } B_{s w, r e c} \text { are assumed as constants } \\
& R_{d, x}=r_{d, x} /\left(\sqrt{2} I_{\text {rated }}\right)\left(\propto \text { silicon area }^{-1}\right)
\end{aligned}
$$

\section{Magnetic machine model}

An expression of the magnetizing inductance $L_{m}$ is shown in (14) for a diametral winding with one slot per pole and per phase:

$$
L_{m}=\frac{3}{2} \frac{4}{\pi} \frac{\mu_{0}}{K_{c} e+h_{m a g}} n_{s}^{2} r_{s} l_{u} p^{2}
$$

where $K_{c}$ is Carter's coefficient [21].

The leakage inductance $L_{l}$ is obtained from a calculation of the magnetic energy stored in a single slot (end windings and tooth tips have been neglected herein), which yields:

$$
L_{l}=2 \mu_{0} \frac{n_{s}^{2} l_{u}}{p^{2}} \frac{h_{\text {slot }}}{3 w_{\text {slot }}}
$$

where $w_{\text {slot }}=\left(2 \pi\left(r_{s}+h_{\text {slot }} / 2\right) k_{\text {slot }}\right) /(6 p)$ is the width of the slot (neglecting curvature effects).

\section{Thermal machine model [22]}

The equivalent thermal circuit of the machine is displayed in Fig. 4. Due to symmetry considerations, only one half of a tooth pitch has been examined. The curvature effects are neglected. The expression for thermal resistances is detailed for the slot only as follows:

$$
\begin{aligned}
R_{\text {th_slot }, r a d} & =\frac{1}{\lambda_{C u}} \frac{h_{\text {slot }}}{l_{u} \frac{w_{s l o t}}{2}} \\
R_{t h \_s l o t, t g} & =\frac{1}{\lambda_{C u}} \frac{\frac{w_{\text {slot }}}{2}}{l_{u} h_{\text {slot }}}
\end{aligned}
$$

$P_{\text {copper }, \text { slot }}$ corresponds to copper losses produced inside a half-slot. $\lambda_{C u}$ corresponds to the equivalent thermal conductivity of the stator winding (copper + insulation), and it is considered constant set equal to $0.5 \mathrm{~W} \cdot \mathrm{m}^{-1} \cdot \mathrm{K}^{-1}$. The value of the temperature rise constraint $\Delta \Theta$ is calculated inside the winding; it corresponds to the temperature rise between the hottest point of the slot and the ambient temperature.

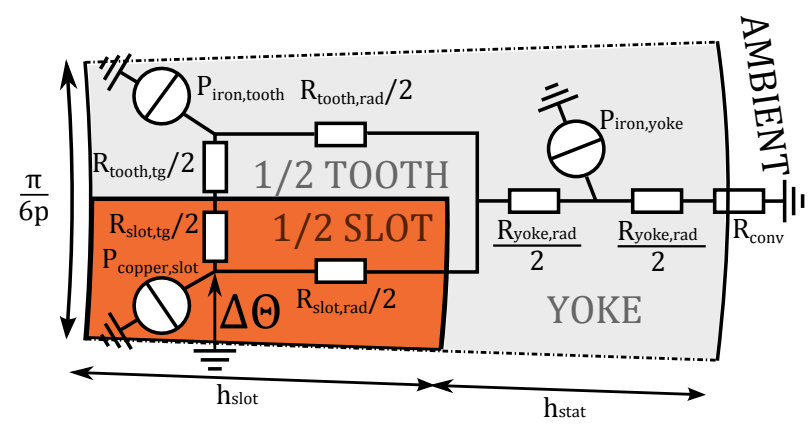

Fig. 4. Equivalent thermal lumped circuit of one half of a tooth pitch of the SPM machine

For simplification concerns, a thermal model of the electronic power converter was not developed since maximum current ratings have been established on the basis of manufacturer guidelines; moreover, it can be considered that cooling will be sized in order to maintain the junction temperature at an acceptable value.

\section{SIZING OPTIMIZATION FLOWCHART}

This article has demonstrated how to evaluate and optimize the performance of a given machine-converter system over an operating profile. Fig. 5 offers the optimization flowchart. The cost of the electric chain, along with the geometric constraints, may be directly assessed from the parameters presented. Losses enable to calculate the objective electrical energy and the thermal constraint. If for a given operating point no solution exists that optimizes $i_{d, i}$, then the corresponding set of optimization parameters will not be selected as part of the overall sizing optimization.

The multi-objective optimization algorithm is based on particle swarm [23]. It is a self implemented version of MOPSO [24] (Multi Objective Particle Swarm Optimization). The size of the swarm has been set at 2,000, and 500 iterations were chosen. Total computation time lasted roughly $1,000 \mathrm{~s}$ on an octo-core PC. To ensure good convergence, the process was run 10 times. The results discussed below represent a combination of the results from each run. 


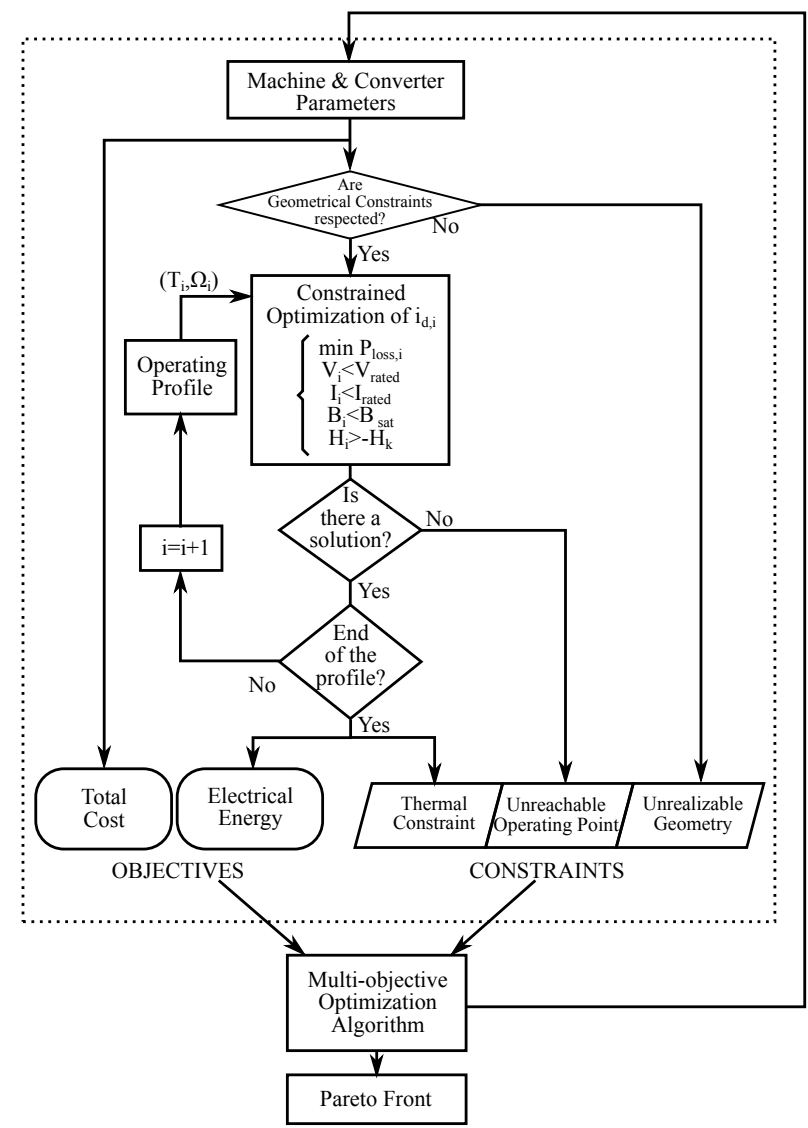

Fig. 5. Optimization flowchart

\section{Application to the Sizing Optimization of a DIRECT-DRIVE GENERATOR-CONVERTER SYSTEM FOR A WAVE ENERGY CONVERTER}

\section{A. Presentation of the SEAREV Wave Energy Converter}

SEAREV (French acronym for Autonomous Electrical System of Wave Energy Conversion) is a wave energy converter (WEC) composed of a float actuated by swell movement. Inside this device, an eccentric mass wheel oscillates relative to the float.

An electric generator (SPM) operating in direct drive converts the mechanical energy of the pendular wheel into electrical energy, thereby causing damping of the relative motion between these two parts. The power electronic converter on the generator side allows the damping torque to be controlled. Because of direct electrical conversion, an electrical energy storage system (ESS) can be placed on the DC-bus to smooth the output electrical power. The SEAREV system therefore provides an application example of this optimization method over a cycle in power generation mode.

\section{B. Damping torque control strategy}

One possible strategy for controlling the conversion torque consists of generating, via the associated machine-converter system, a viscous friction torque, i.e. introducing a resistant torque proportional to the angular velocity in addition to a levelling of the converted mechanical power [25]. The idea

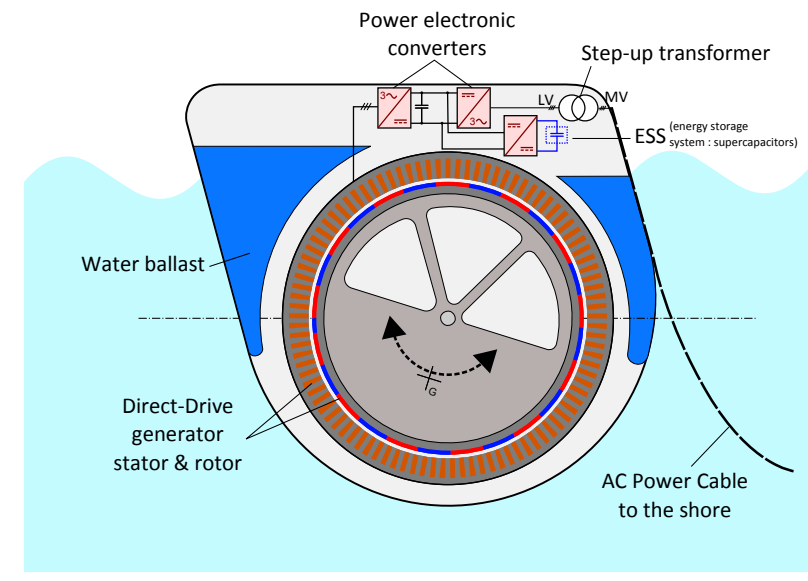

Fig. 6. Schematic diagram of the SEAREV WEC operating principle

TABLE V

OPTIMIZATION DAMPING PARAMETERS

\begin{tabular}{llll}
\hline Symbol & Description & Range & Units \\
\hline$\beta$ & Viscous damping torque coefficient & {$[0.5 ; 15]$} & $M N . m . s^{-1}$ \\
$P_{l e v}$ & Mechanical levelling power & {$[0.1 ; 3]$} & $M W$ \\
\hline
\end{tabular}

behind this levelling is to downsize the electronic power converter without an excessive loss of produced energy potential. Indeed, without levelling, the power can be very high but during very few time. It will induced cost overrun without increasing the income. For each operating point, torque $T_{i}$ can thus be correlated with angular velocity $\Omega_{i}$ by (18).

$$
T_{i}=\left\{\begin{array}{lll}
\beta \Omega_{i} & \text { if } \quad \beta \Omega_{i}^{2}<P_{l e v} \\
\frac{P_{l e v}}{\Omega_{i}} & \text { if } & \beta \Omega_{i}^{2} \geq P_{l e v}
\end{array}\right.
$$

where $\beta$ is the viscous damping coefficient and $P_{l e v}$ is the mechanical levelling power. We refer herein as "Damping Parameters" the set $\left(\beta, P_{l e v}\right)$.

\section{Numerical modelization}

The hydrodynamic and mechanical numerical modelization of the SEAREV has been developed at the Ecole Centrale de Nantes [26]. This model permits to compute torque and angular velocity time series of the direct drive electrical generator. Because of strong hydro-mechanical coupling, they depend on the two damping parameters $\beta$ and $P_{\text {lev }}$ previously defined. Others parameters have to be provided for the numerical simulation such as the sea state in the form of two values $H_{1 / 3}$ (the significant height) and $T_{p}$ (the spectral peak period). Simulations are conducted over $1256 \mathrm{~s}$ with a time-step of $0.1 \mathrm{~s}$. The computation time of such a simulation is about 30 s. Fig. 7 gives examples of angular velocity and mechanical torque time series (between $t=500 \mathrm{~s}$ and $t=800 \mathrm{~s}$ ) corresponding to $\beta=4.10^{6} \mathrm{~N} . \mathrm{m} . \mathrm{s}^{-1}$ and $P_{l e v}=1 \mathrm{MW}$ and for typical sea state $\left(H_{s}=3 m, T_{p}=8 s\right)$. Fig. 8 shows the corresponding operating cycle in the torque-speed plane. The area of each plotted point is proportional to its mechanical energy (the cumulated duration of the operating point multiply by its mechanical power $T_{i} \Omega_{i} d_{i}$ ). 

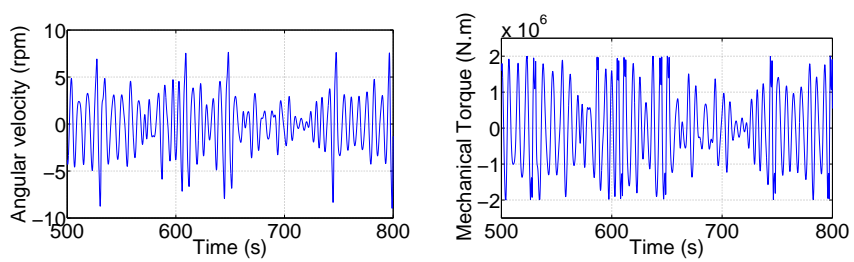

Fig. 7. Examples of operating time series (angular velocity and torque time series) extract of $200 \mathrm{~s}$ of a total time cycle equals $1,256 \mathrm{~s}$. Damping parameters are $\beta=4.10^{6} \mathrm{~N} . \mathrm{m} . \mathrm{s}^{-1}$ and $P_{l e v}=1 \mathrm{MW}$, then the maximum torque is $2 \mathrm{MN} . \mathrm{m}$

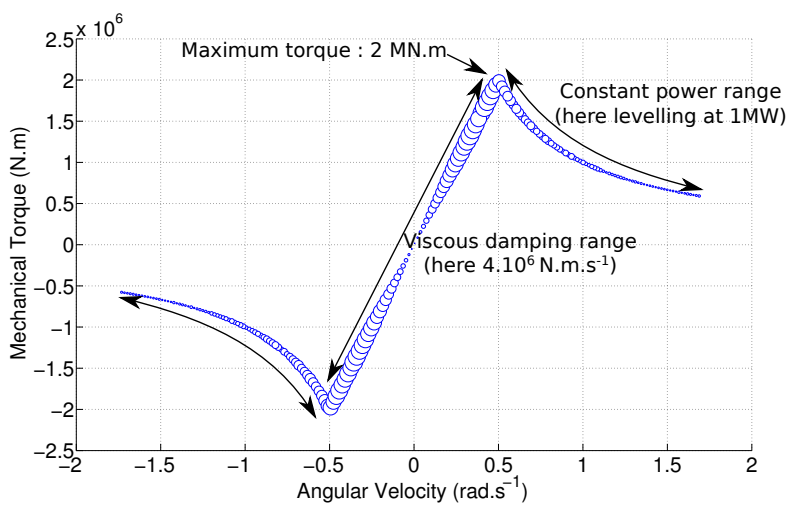

Fig. 8. Example of an operating profile in the $(T, \Omega)$ plane - The area of each point is proportional to its mechanical energy (i.e. cumulated duration $*$ mechanical power). Damping parameters are $\beta=4.10^{6} \mathrm{~N} \cdot \mathrm{m} . \mathrm{s}^{-1}$ and $P_{l e v}=1 M W$, then the maximum torque is $2 \mathrm{MN} . \mathrm{m}$

\section{Sensitivity of the damping parameters}

Values of each damping parameters have a strong influence on the torque speed operating profile and therefore on the mechanical recoverable energy. To illustrate this fact, Fig. 9 shows the average mechanical power (recoverable energy before electrical conversion) over the operating profile according to the two damping parameters $\beta$ and $P_{l e v}$ for the sea state $\left(H_{s}=3 m, T_{p}=8 s\right)$. It can be seen that the mechanical maximum power to convert can be limited up to $1.2 \mathrm{MW}$ without excessive loss of average power (energy potential).

For each value of $P_{l e v}$, there is one value of $\beta$ maximizing the average mechanical power. Values of damping parameters have also an influence on the maximum mechanical torque over the operating profile which is equal to $T_{\max }=\sqrt{\beta P_{l e v}}$ (cf Fig. 8) . It is then very difficult to find a priori the best sets of damping parameters. That is why, they have to be optimized in the same way as the machine-converter system sizing parameters. A comparison between two optimizations is presented in the following (cf Fig. 10). The first one is with $\beta$ and $P_{l e v}$ taken into account in the optimization parameters. The second one is with fixed damping parameters.

\section{E. Numerical application to SEAREV WEC}

The level of power being considered $(\sim 1 \mathrm{MW})$ allows adopting the hypothesis previously described on transient thermal states, with the temperature rise constraint then being calculated on the basis of the average value of copper and iron losses. The losses coefficients for the power electronic

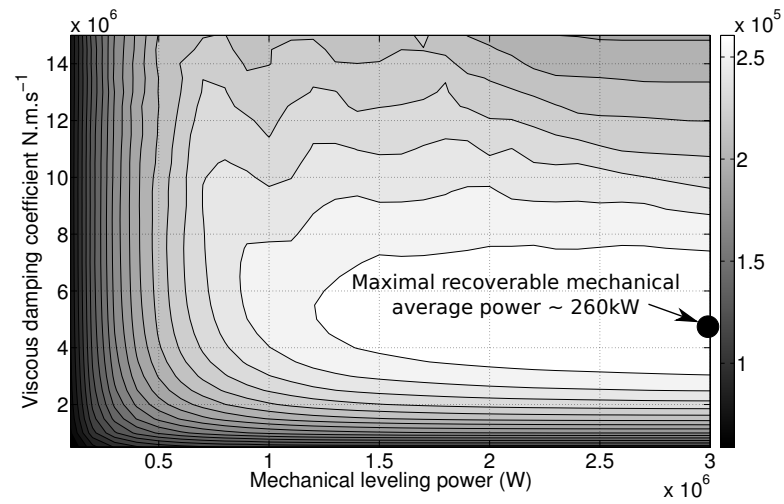

Fig. 9. Recoverable mechanical average power (before electrical conversion) in Watt according to the mechanical levelling power and the viscous damping coefficient

converters were given previously for a maximum voltage rating of $3,300 \mathrm{~V}$.

In this example, the direct axis current is optimized at each operating point in order to minimize total machine-converter system losses. The numerical method employed to perform this constrained optimization has been described in Section II-D. The number of discrete values tested for $i_{d}$ has been fixed at 100 in the bounded interval $\left[-I_{\text {rated }} ; 0\right]$.

Because the solutions with a cost higher than $1 \mathrm{M} €$ will never be cost effective, a constraint has been added to limit the cost below this threshold.

The optimization results are presented on Fig. 10. These two Pareto fronts indicate the sets of best solutions relative to both the machine-converter system cost and average produced electrical power on the sea state $\left(H_{s}=3 m, T_{p}=8 s\right)$. More thorough studies should take into account all the encountered sea states and their probability of appearance on a specific wave site.

It is shown on Fig. 10 that the simultaneous optimization of the machine-converter system and the damping parameters of the SEAREV WEC enable to extend the set of non dominated solutions, compared to the optimization with fixed values of $\beta$ and $P_{l e v}$. For the first optimization (coupled), $\beta$ and $P_{l e v}$ vary respectively in the bounded intervals precised in Tab. V. As for the second optimization (uncoupled), $\beta$ and $P_{l e v}$ are fixed at $\left(5 M N . m . s^{-1}, 1 M W\right)$.

For the highest costs solutions of the coupled optimization, damping parameters are chosen in such a way that the incoming average mechanical power is maximum (here $260 \mathrm{~kW}$ cf Fig. 9) regardless of the peak mechanical power : $\left(\beta=4.5 * 10^{6}\right.$ N.m.s $s^{-1}, P_{l e v}=3 M W$ cf Fig. 11). With the system cost decrease, $P_{l e v}$ is the first damping parameter to decrease until it arrives in the vicinity of $1.5 \mathrm{MW}$. The average mechanical power is almost not affected by the levelling power above this value, but the mechanical peak power decreases greatly. That is why in this part of the Pareto front, the average produced electrical power does not decrease a lot, whereas the cost falls significantly. Below the value of $1.5 \mathrm{MW}$, the two damping parameters decrease simultaneously and the mechanical incident power as well. 


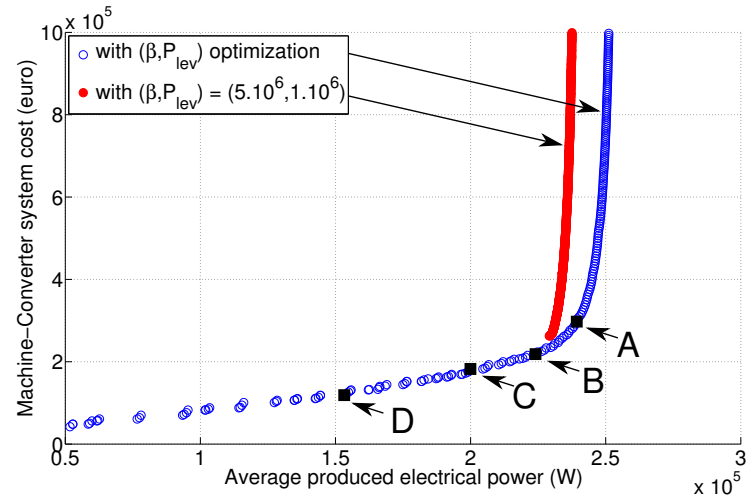

Fig. 10. Pareto fronts with and without damping parameters optimization

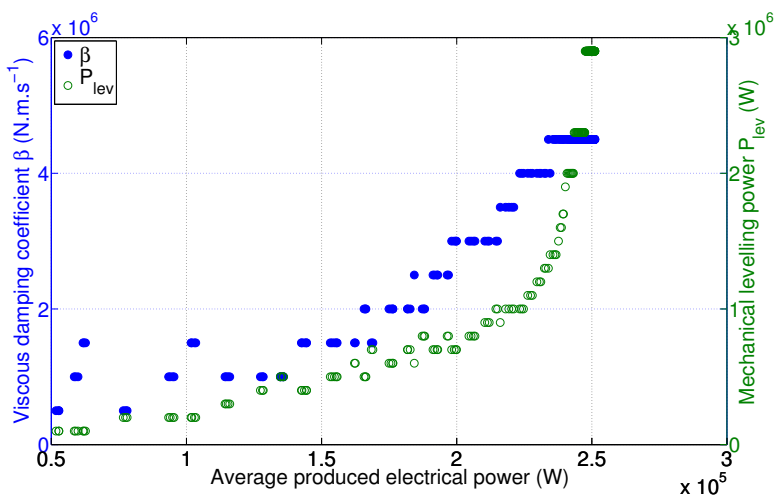

Fig. 11. Optimal damping parameters according to the average produced electrical power for the coupled optimization

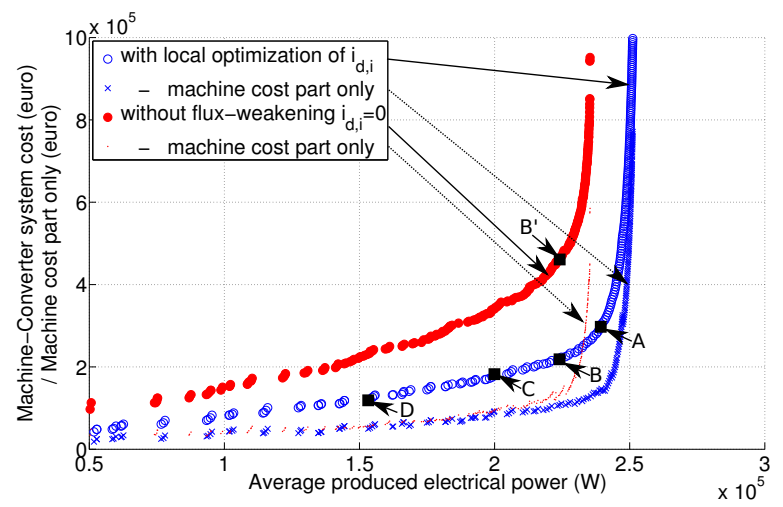

Fig. 12. Pareto fronts with and without flux-weakening possibility

A claimed originality of the presented methodology of sizing is to take into consideration the local constrained optimization of the d-axis current $i_{d, i}$ for each operating point (cf section II-D). This step allows to take some constraints into account but also ratings of the power electronic converter and then implicitly flux-weakening possibility. Figure 12 compares the Pareto front obtained with the presented method (i.e. with flux-weakening) and these obtained with an optimization where the d-axis current is always set to 0 (i.e. without fluxweakening). Solutions without flux weakening exhibit always higher system cost for the same average produced electrical power. This cost overrun is mainly due to the power electronic converter cost. Indeed, the levelling of the mechanical incident power via the damping parameter $P_{l e v}$, can be achieve by flux-weakening without an important oversizing of the power electronic converter as it can be seen on Fig. 13 (on the bottom) where $S_{\text {conv }} / P_{\text {lev }} \sim 1$. Otherwise (i.e. without fluxweakening possibility), the required apparent power of the power electronic converter is more related to the product of the maximum torque by the maximum speed (corner power) of the operating cycle as it can be seen on Fig. 13 (on the top $\left.S_{\text {conv }} /\left(T_{\max } \Omega_{\max }\right) \sim 1\right)$. Then, decrease the mechanical levelling power without permitting a flux-weakening is not interesting to reduce the cost of the power electronic converter because it increases the corner power. The sizing parameters of five specific solutions (denoted A,B,C,D and B') are detailed in Tab. VI.

TABLE VI

Five DETAILED SOLUTIONS OF THE PARETO FRONT

\begin{tabular}{llccccc}
\hline Symbol & Units & $\mathbf{A}$ & $\mathbf{B}$ & $\mathbf{C}$ & $\mathbf{D}$ & $\mathbf{B}$ \\
\hline$P_{\text {average }}$ & $\mathrm{kW}$ & 239 & 224 & 200 & 153 & 224 \\
$C_{\text {drive }}$ & $\mathrm{k} €$ & 297 & 218 & 182 & 119 & 461 \\
$C_{\text {mach }}$ & $\mathrm{k} €$ & 142 & 107 & 92 & 52 & 131 \\
$C_{\text {conv }}$ & $\mathrm{k} €$ & 167 & 111 & 90 & 69 & 329 \\
\hline$\beta$ & MN.m.s-1 & 4.5 & 4 & 3 & 1.5 & 3 \\
$P_{\text {lev }}$ & $\mathrm{MW}$ & 1.7 & 1 & 0.7 & 0.5 & 3 \\
$S_{\text {conv }}$ & $\mathrm{MVA}$ & 1.71 & 1.07 & 0.79 & 0.54 & 5.04 \\
$l_{u}$ & $\mathrm{~cm}$ & 54 & 56 & 46 & 41 & 53 \\
$r_{\text {s }}$ & $\mathrm{m}$ & 4.77 & 4.79 & 4.80 & 4.85 & 4.79 \\
$p$ & - & 113 & 142 & 158 & 208 & 94 \\
$e$ & $\mathrm{~mm}$ & 5.2 & 5.1 & 4.7 & 4.7 & 5.2 \\
$h_{\text {mag }}$ & $\mathrm{mm}$ & 17 & 9.1 & 7.8 & 4.7 & 21 \\
$h_{\text {rot }}$ & $\mathrm{cm}$ & 3.6 & 2.3 & 2.1 & 1.1 & 4.7 \\
$h_{\text {slot }}$ & $\mathrm{cm}$ & 17.5 & 15.5 & 17.3 & 10.9 & 11.3 \\
$h_{\text {stat }}$ & $\mathrm{cm}$ & 4.1 & 2.6 & 2.8 & 1.1 & 4.8 \\
$k_{\text {slot }}$ & $\%$ & 49 & 59 & 58 & 65 & 43 \\
$n_{s}$ & - & 321 & 426 & 474 & 621 & 94 \\
\hline$M_{\text {machine }}$ & $\mathrm{ton}$ & 29 & 22 & 20 & 11 & 25 \\
$L_{m}$ & $\mathrm{mH}$ & 2.4 & 3.6 & 3.4 & 3.8 & 0.2 \\
$L_{l}$ & $\mathrm{mH}$ & 3.2 & 4.3 & 5.0 & 4.8 & 0.2 \\
$R_{\text {s }}$ & $\mathrm{m} \Omega$ & 22 & 34 & 31 & 62 & 3.2 \\
$\Phi_{e}$ & $\mathrm{~Wb}$ & 8.5 & 6.8 & 5.4 & 3.8 & 2.9 \\
\hline & & & & & &
\end{tabular}

Fig. 14 shows the power-speed operating areas of B and B' solutions along with the operating profile corresponding to their damping parameters in the mechanical power-speed plane. The area of each plotted operating point of the cycle is proportional to its cumulated duration multiply by its mechanical power $\left(T_{i} \Omega_{i} d_{i}\right)$. The gray scale indicates the $\mathrm{d}$ axis current contour plot of the machine-converter system for each feasible operating point. On the left, this current is always set to 0 because flux-weakening is not permitted. On the right, d-axis current is optimized according to the total system losses criterion. These two solutions produce the same average electrical power but B' solution, which is optimized without flux-weakening possibility, costs twice as much as B solution (cf. Table VI). The mechanical power levelling is slighter for B' solution because a lower levelling would have increase the corner power and then the apparent power of the converter. For B solution, mechanical power levelling is more significant because flux-weakening is permitted and the apparent power is no more related to the corner power but to the levelling power. 


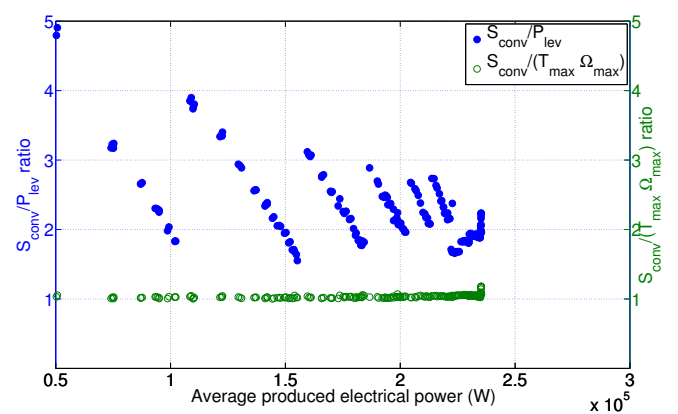

(a) without flux-weakening

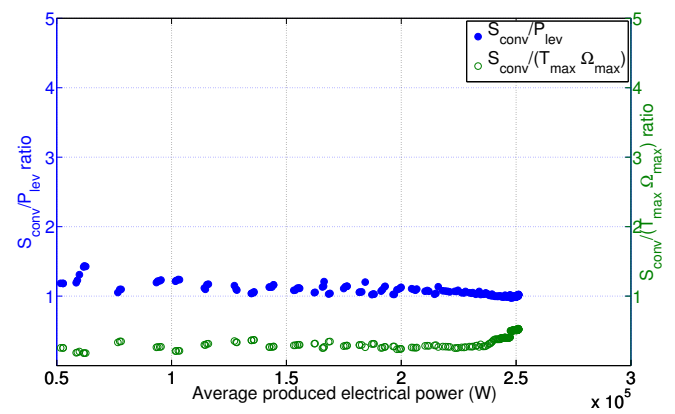

(b) with flux-weakening

Fig. 13. $S_{\text {conv }} / P_{\text {lev }}$ and $S_{\text {conv }} /\left(T_{\max } \Omega_{\max }\right)$ ratios according to to the average produced electrical power for the optimization without flux-weakening (on the top) and with flux-weakening (on the bottom)

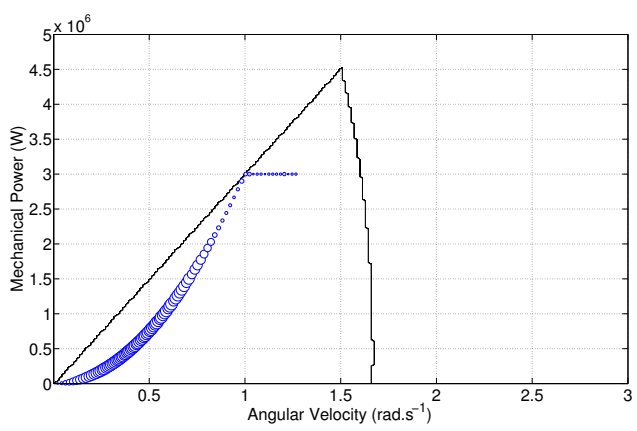

(a) without flux-weakening

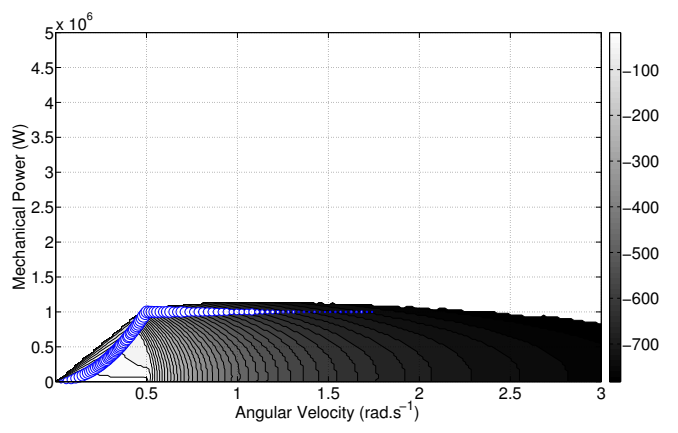

(b) with flux-weakening

Fig. 14. Mechanical power-speed operating area and contour plot of the d-axis current (in Ampere) for two specific solutions. On the top, B' solution, optimized without flux weakening possibility $\left(i_{d}=0 \forall T_{i}, \Omega_{i}\right)$. On the bottom, B solution, optimized with flux weakening possibility $\left(i_{d, i}=\right.$ $\operatorname{argmin} P_{\text {loss }, i}\left(T_{i}, \Omega_{i}\right)$ under constraints cf. Sec. II-D). The rated current

$I_{\text {rated }}^{i_{d}}$ equals $S_{\text {conv }} /\left(3 V_{\text {rated }}\right)$. ( $777 A$ for B and $3660 A$ for B')

\section{CONCLUSION}

This paper has presented a machine-converter system optimization methodology applied over an operating profile with a strong coupling between the machine and the power electronic converter. The aim was optimizing the sizing of an all-electric conversion chain for a wave energy conversion system. This methodology proves to be applicable to any system in which a machine-converter system is operating at variable speed, like for electric traction or renewable energy conversion. A number of simplifying hypotheses were adopted, primarily to save computation time, yet the integration of more complex models would not pose a problem from a methodological standpoint. A machine model based on finite elements could even be used to more accurately calculate magnetic losses, particularly under conditions of considerable flux weakening, although computation time would rise substantially. A transient thermal model could also improve quality of results especially for applications where thermal time constants of the machine are near from the loss variation periods. Finally, taking the cost of manufacturing process and these of inactive parts into account in the cost of the machine could lead to different optimal solutions [27].

\section{REFERENCES}

[1] N. Boules, "Design optimization of permanent magnet DC motors," IEEE Transactions on Industry Applications, vol. 26, no. 4, pp. 786-792, Jul. 1990

[2] G. Slemon and X. Liu, "Modeling and Design Optimization Of Permanent Magnet Motors," Electric Power Components and Systems, vol. 20, no. 2, pp. 71-92, Mar. 1992.

[3] F. Messine, B. Nogarede, and J.-L. Lagouanelle, "Optimal design of electromechanical actuators: a new method based on global optimization," IEEE Transactions on Magnetics, vol. 34, no. 1, pp. 299-308, Jan. 1998.

[4] N. Bianchi and S. Bolognani, "Design optimisation of electric motors by genetic algorithms," IEE Proceedings - Electric Power Applications, vol. 145 , no. 5, pp. 475-483, Sep. 1998.

[5] K. Laskaris and a.G. Kladas, "Internal Permanent Magnet Motor Design for Electric Vehicle Drive," IEEE Transactions on Industrial Electronics, vol. 57, no. 1, pp. 138-145, Jan. 2010.

[6] D. Dorrell, M. Hsieh, M. Popescu, L. Evans, D. A. Staton, and V. Grout, "A Review of the Design Issues and Techniques for Radial-Flux Brushless Surface and Internal Rare-Earth Permanent Magnet Motors," IEEE Transactions on Industrial Electronics, 2010.

[7] N. Bianchi and S. Bolognani, "Unified approach to the analysis and design of an AC motor drive for flux-weakening operations," Conference Record of 1998 IEEE Industry Applications Conference. Thirty-Third IAS Annual Meeting, vol. 1, pp. 95-102, Oct. 1998.

[8] E. Lovelace, T. Jahns, and J. Lang, "Impact of saturation and inverter cost on interior PM synchronous machine drive optimization," IEEE Transactions on Industry Applications, vol. 36, no. 3, pp. 723-729, 2000.

[9] J. Figueroa, J. Cros, and P. Viarouge, "Relative Sizing of Inverter and Surface Mount PM Motor for Traction Applications," in IEEE International Symposium on Industrial Electronics, vol. 4, no. 3, Montréal, Jul. 2006, pp. 2254-2259.

[10] T. M. Jahns, "Flux-Weakening Regime Operation of an Interior Permanent-Magnet Synchronous Motor Drive," IEEE Transactions on Industry Applications, vol. 23, no. 4, pp. 681-689, Jul. 1987.

[11] S. Morimoto, Y. Takeda, T. Hirasa, and K. Taniguchi, "Expansion of operating limits for permanent magnet motor by current vector control considering inverter capacity," IEEE Transactions on Industry Applications, vol. 26, no. 5, pp. 866-871, Sep. 1990.

[12] S. Morimoto, Y. Tong, Y. Takeda, and T. Hirasa, "Loss minimization control of permanent magnet synchronous motor drives," IEEE Transactions on Industrial Electronics, vol. 41, no. 5, pp. 511-517, Oct. 1994. 
[13] C. Mademlis, J. Xypteras, and N. Margaris, "Loss minimization in surface permanent-magnet synchronous motor drives," IEEE Transactions on Industrial Electronics, vol. 47, no. 1, pp. 115-122, Feb. 2000.

[14] C. Cavallaro, a.O. DiTommaso, R. Miceli, a. Raciti, G. Galluzzo, and M. Trapanese, "Efficiency Enhancement of Permanent-Magnet Synchronous Motor Drives by Online Loss Minimization Approaches," IEEE Transactions on Industrial Electronics, vol. 52, no. 4, pp. 1153-1160, Aug. 2005

[15] L. Chedot, G. Friedrich, J.-M. Biedinger, and P. Macret, "Integrated Starter Generator: The Need for an Optimal Design and Control Approach. Application to a Permanent Magnet Machine," IEEE Transactions on Industry Applications, vol. 43, no. 2, pp. 551-559, Mar. 2007.

[16] O. de la Barrière, S. Hlioui, H. Ben Ahmed, M. Gabsi, and M. LoBue, "PM Axial Flux Machine Design for Hybrid Traction," Oil \& Gas Science and Technology Revue de l'Institut Français du Pétrole, vol. 65, no. 1, pp. 203-218, Nov. 2009.

[17] S. Kreuawan, F. Gillon, and P. Brochet, "Optimal design of permanent magnet motor using multidisciplinary design optimization," in Proceedings of the18th International Conference on Electrical Machines (ICEM), Vilamoura, Sep. 2008, pp. 1-6.

[18] J. Lindstrom, J. Hellsing, and J. Luomi, "Design of high-efficiency electrical motors for a hybrid electric vehicle," in 13th International Electric Vehicle Symposium, EVS-13, Osaka, 1996.

[19] A. Tessarolo, D. Giulivo, and M. Mezzarobba, "A system-level approach to the optimal dimensioning of induction-motor variable-frequency drives," in Power Electronics and Applications, 2009. EPE'09. 13th European Conference on. IEEE, 2009, pp. 1-10.

[20] J. Aubry, H. Ben Ahmed, and B. Multon, "Bi-Objective Sizing Optimization of a PM Machine Drive on an Operating Profile," in Proceedings of the International Conference on Electrical Machines (ICEM), Roma, Sep. 2010, pp. 1-7.

[21] J. Gieras and M. Wing, Permanent magnet motor technology: design and applications, 2nd ed. Marcel Dekker, 2002.

[22] A. Boglietti, A. Cavagnino, D. Staton, M. Shanel, M. Mueller, and C. Mejuto, "Evolution and modern approaches for thermal analysis of electrical machines," IEEE Transactions on Industrial Electronics, vol. 56, no. 3, pp. 871-882, Mar. 2009.

[23] H. M. Hasanien, "Particle Swarm Design Optimization of Transverse Flux Linear Motor for Weight Reduction and Improvement Thrust Force," IEEE Transactions on Industrial Electronics, 2010.

[24] C. a. Coello Coello and M. Reyes-Sierra, "Multi-Objective Particle Swarm Optimizers: A Survey of the State-of-the-Art," International Journal of Computational Intelligence Research, vol. 2, no. 3, pp. 287-308, 2006.

[25] M. Ruellan, H. Ben Ahmed, B. Multon, C. Josset, A. Babarit, and A. Clement, "Design Methodology for a SEAREV Wave Energy Converter," IEEE Transactions on Energy Conversion, vol. 25, no. 3, pp. 760-767, Sep. 2010.

[26] A. Babarit, A. H. Clement, and J.-C. Gilloteaux, "Optimization and Time-Domain Simulation of the SEAREV Wave Energy Converter," in 24th International Conference on Offshore Mechanics and Arctic Engineering, vol. 2, no. Omae. Halkidiki: ASME, Jun. 2005, pp. $703-712$.

[27] A. McDonald, M. Mueller, and H. Polinder, "Structural mass in direct-drive permanent magnet electrical generators," IET Renewable Power Generation, vol. 2, no. 1, p. 3, Mar. 2008.

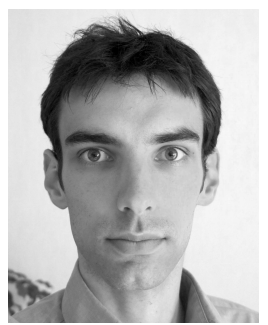

Judicaël Aubry was born in Nantes, France, in 1985. He graduated in electrical engineering from the Ecole Normale Supérieure de Cachan (ENS Cachan), Cachan, France, in 2008. He is currently working toward the Ph.D. degree in electrical engineering at the SATIE laboratory, ENS Cachan Bretagne, Centre National de la Recherche Scientifique (CNRS), Université Européenne de Bretagne (UEB), Bruz, France. His current research interests include wave energy conversion, electrical drive optimization, particle swarm optimization and energy storage.

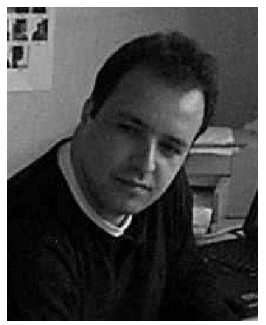

Hamid Ben Ahmed received the $\mathrm{PhD}$ degree and HDR degree in 1994, and 2006 respectively. From 1994 to 1997, he was a Research Associate in the SATIE laboratory. Since 1997, he was an Assistant Professor in the Mecatronique Department of "Ecole Normale Supérieure de Cachan," Brittany Branch, France. His research interest include the design, modelling and optimisation of novel topologies of electromagnetic actuators and generators, and the optimisation of renewable energy systems.

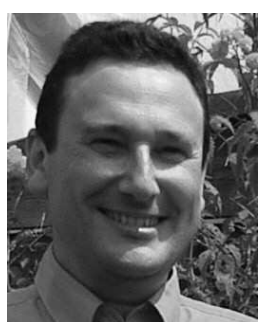

Bernard Multon was born on 1960. He received the M.S. degree in electrical engineering from the Ecole Normale Supérieure de Cachan, Cachan, France, in 1981, Electrical Engineering Agrégation in 1982 and the Ph.D. degree from the University of Paris 6, Paris, France, in 1985. From 1988 and 1995, he was Assistant Professor in the Electrical Engineering Department, Ecole Normale Supérieure de Cachan (ENS de Cachan), and Leader of the Research Special Actuator Design Group in LESiR-CNRS. Since 1995, he is Full Professor in the Brittany Site of ENS de Cachan (Ker Lann Campus in south of Rennes). He teaches in the Mechatronics Department and he conducts his research in SETE team of laboratory SATIE-CNRS on electromechanical chain sizing and new electrical energy conversion systems (renewable and human power). 